\title{
MENINGKATKAN KEMAMPUAN SETORAN HAFALAN AL-QUR'AN MELALUI METODE TALAQQI PADA SISWA KELAS VIB SEKOLAH DASAR ISLAM YAKMI TAHUN 2018
}

\author{
Imam Mashud \\ Sekolah Dasar Islam YAKMI Kota Tangerang \\ J1. Balita XI No.189, Kunciran Indah, Pinang, Kota Tangerang, Banten 15144 \\ Email: imam_mashud@yahoo.com
}

\begin{abstract}
The memorizing conditions in Islamic elementary school YAKMI year aws have never been properly identified and recorded on the sheets of mutaba'ah, so it is difficult to find weaknesses and strengths possessed by students in memorizing Al-Qur'an . The implementation of memorizing deposits using the talaqqi method for students, especially class VI B, the teacher records the results of the student deposit on the mutaba'ah sheet given by the school. Simple recording criteria made by the school, if done continuously, the results will be seen without manipulating the data to make it look good. The purpose of this study was to determine the ability of VIB class students in Al-Qur'an memorization deposits, the use of the talaqqi method for students in YAKMI Islamic elementary schools, and the results of Al-Qur'an memorization deposits through the talaqqi method. The results obtained from the memorization activities of VIB class students using the talaqqi method are student memorization deposits that have been conducted from July to November 2018, on average all students in the VIB class have memorized 20 letters or 55\% of the letters in juz to -30, 36 letters have been memorized by all VIB class students. Thus very optimistic for to target memorized on the 30th juz as many as 36 letters can be achieved and can be carried out in the Al-Qur'an memorization public test in April 2019.
\end{abstract}

Keywords:

Student memorizing the deposit; talaqqi method

\begin{abstract}
Abstrak
Keadaan hafalan pada siswa TPA SD Islam pada tahun ajaran sebelumnya tidak pernah teridentifikasi dengan baik dan tercatat pada lembar mutaba'ah, sehingga sulit untuk dicari kelemahan dan kekuatan yang dimiliki oleh siswa dalam hafalan Al-Qur'an.. Kegiatan pelaksanaan setoran hafalan dengan menggunakan metode talaqqi pada siswa khususnya kelas VI B, maka guru mencatat hasil setoran siswa pada lembar mutaba'ah yang telah diberikan oleh pihak sekolah. Kriteria pencatatan sederhana yang dibuat oleh sekolah, apabila dilakukan secara kontinyu maka akan terlihat hasilnya tanpa melakukan manipulasi data agar terlihat bagus. Adapun tujuan dari penelitian ini adalah untuk mengetahui kemampuan siswa kelas IIA dalam setoran hafalan Al-Qur'an, penggunaan metode talaqqi pada siswa di sekolah dasar Islam YAKMI, dan hasil dari setoran hafalan Al-Qur'an melalui metode talaqqi. Hasil yang didapat dari kegiatan setoran hafalan siswa kelas VIB dengan menggunakan metode talaqqi adalah setoran hafalan siswa yang telah dilakukan dari bulan Juli sampai bulan November 2018, rata-rata seluruh siswa pada kelas VIB sudah hafal 20 surat atau 55\% dari jumlah surat pada juz ke-30 yakni 36 surat sudah dihafal oleh seluruh siswa kelas VIB. Dengan demikian sangat optimis untuk target hafal pada juz ke-30 sebanyak 36 surat dapat tercapai dan dapat dilakukan uji publik hafalan Al-Qur' an pada bulan April 2019.
\end{abstract}

Kata Kunci:

Setoran hafalan siswa; metode talaqqi

\section{A. PENDAHULUAN}

Al-Qur'an merupakan kitab suci umat Islam berupa firman Allah SWT yang di turunkan dengan perantara Malaikat Jibril kepada Rasulullah Muhammad S.A.W. Al-Qur'an adalah wahyu Illahi sebagai salah satu rahmat yang tak dapat disamakan dengan kitab-kitab sebelumnya yang telah diturunkan Allah kepada para nabi seperti Zabur Taurat Injil atau Suhuf-suhuf lainnya. Namun Al-Qur'an dijadikan mukjizat yang menjadi pedoman dan penuntun hidup bagi manusia yang ingin mencapai kebahagiaan hidup di dunia dan akhirat. Karena isinya mencakup segala pokok-pokok syariat yang telah disempurnakan dari kitab-kitab sebelumnya.
Oleh sebab itu setiap muslim wajib mempelajari Al-Qur'an agar memiliki pengetahuan, pemahaman dan pengertian tentang aspek-aspek pendidikan, sosial, budaya, kisah dan suri tauladan sehingga dapat mengamalkannya dalam kehidupan sehari-hari. Pelajaran Al-Qur'an perlu diberikan kepada anak sejak usia balita, kanak-kanak, remaja bahkan dewasa sekalipun karena Al-Qur'an adalah suatu kitab yang bersifat universal yang akan menjelaskan secara tersirat dan tersurat makna di dalamnya. Maka secara individu wajib mengimani Al-Qur'an sebagai kitab umat Islam. Oleh karena itu, mempelajari Al-Qur'an menjadi sebuah keharusan bagi semua 
pihak baik di lingkungan formal, informal, maupun non formal.

Perintah membaca merupakan perintah yang diberikan oleh Allah SWT kepada manusia. Manusia akan memiliki pengetahuan dan wawasan yang luas dikarenakan membaca, serta mengantarkan manusia kepada derajat kemanusiaan yang sempurna. ${ }^{1}$ Sebagaimana firman Allah dalam Surat Al-Baqarah ayat 121 yang berbunyi:

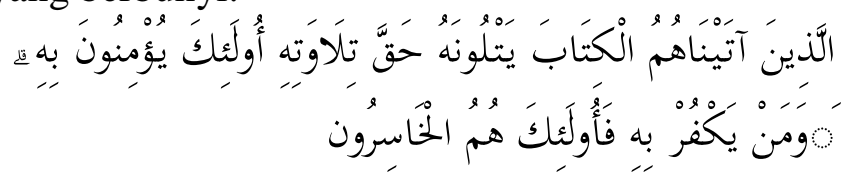

Artinya: Orang-orang yang telah Kami berikan Al Kitab kepadanya, mereka membacanya dengan bacaan yang sebenarnya, mereka itu beriman kepadanya. Dan barang siapa yang ingkar kepadanya, maka mereka itulah orang-orang yang rugi (Q.S AlBaqarah: 121$)^{2}$

Selain membaca, menghafal juga memiliki peran penting dalam menjamin kemurnian dan kesucian Al-Qur'an, pada masa Rasulullah pelestarian Al-Qur'an dengan cara hafalan, para sahabat menghafal semua wahyu yang disampaikan oleh Rasulullah sendiri. Beberapa sahabat menulis wahyu tersebut atas perintah Rasulullah. Hal ini merupakan salah satu upaya untuk menjaga kemurnian dan keaslian Al-Qur'an agar tetap terpelihara keutuhannya.

Menghafal Al-Qur'an merupakan hal yang sangat penting untuk dilaksanakan sejak usia dini. Hal ini mengingat ibadah shalat bagi umat Islam diwajibkan untuk menghafal Al-Qur'an, di mana dalam setiap melaksanakan ibadah shalat dilafalkan ayat-ayat Alquran. Menghafal AlQur'an merupakan sebuah usaha yang paling efektif dalam menjaga kemurnian Alquran yang agung. Dengan hafalan tersebut berarti meletakkan isi Al-Quran pada hati penghafal. Dan

\footnotetext{
${ }^{1}$ M. Quraish, Shihab, Membumikan al-Quran, (Jakarta:

Lentera Hati, Vol. 15, 2002), hal. 170.

${ }^{2}$ Departemen Agama RI, Al-Q ur' an Tajwid dan

Terjemahnya, (Bandung: Diponegoro, 2016), hal. 19
}

menurut Raghib dan Abdurrahman, "tempat tersebut (hati) merupakan tempat penyimpanan yang paling aman, terjamin, serta tidak bisa dijangkau oleh musuh dan para pendengki serta penyelewengan-penyelewengan yang dilakukan."3

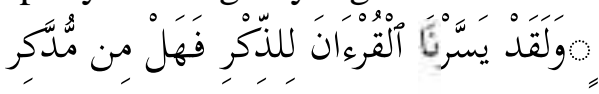

Artinya: Dan sesungguhnya telah Kami mudahkan Al-Quran untuk pelajaran, maka adakah orang yang mengambil pelajaran? (Q.S AlQamar: 17) ${ }^{4}$

Para ulama bersepakat bahwa hukum menghafal Al-Qur'an adalah fardhu kifayah. Jika di antara anggota masyarakat dapat melaksanakan dan mampu menghafal Al-Qur'an maka terlepas dosa atas yang lainnya. Dan jika diabaikan dan tidak mau menghafalnya maka berdosa semua masyarakat di daerah tersebut. Pada prinsipnya kekuatan hukum seperti ini dimaksudkan untuk menjaga Al-Qur'an dari pemalsuan, pergantian dan perubahan yang telah terjadi bagi kitab-kitab sebelumnya yaitu Zabur, Taurat, dan Injil. ${ }^{5}$

Kondisi kemampuan membaca dan menghafal Al-Qur'an pada siswa kelas VI Sekolah Dasar Islam YAKMI pada saat ini masih butuh perhatian, sekalipun sebagian besar siswa adalah beragama Islam. Ternyata kemampuan membaca Al-Qur'annya sangatlah minim. Lemahnya kemampuan baca Al-Qur' an tentu saja akan berimplikasi terhadap berkurangnya intensitas untuk selalu berinteraksi dengan AlQur'an yang pada gilirannya akan menyebabkan jauhnya pengetahuan dini siswa tersebut terhadap pengamalan Al-Qur'an itu sendiri. Demikian pula dalam menghafal ayat suci Al-Qur'an siswa kurang mampu menghafal dengan baik sebagian siswa kurang teliti dalam pengaturan ayat perayat, dan kurang lancar menghafal. Minat menghafal masih minim dan bahkan suatu beban yang berat bagi siswa.

\footnotetext{
3 Raghib As-Sirjani dan Abdurrahman A. Khaliq, Cara Cerdas Hafal Al-Qur' an, (Solo: Aqwam, 2007), hal, 45.

4 Departemen Agama RI, Al-Qur'an Tajwid dan Terjemahnya, op.cit, hal. 529

5 Sa'adulloh, Cara Cepat Menghafal Al-Qur'an, (Jakarta: Gema Insani, 2008), hal. 19
} 
Berdasarkan pengalaman dan pengamatan penulis selama mengajar di SD Islam YAKMI, maka di dapat tujuan dari penggunaan metode tallaqi adalah untuk menjaga kesahihan bacaan Al-Quran, sehingga ketika bacaan seseorang murid akan ditegur secara direct oleh guru jika terdapat kesalahan bacaan, murid dapat melihat sendiri pergerakan mulut guru apabila menyebut bacaan Al-Qur'an, murid lebih memberi perhatian jika guru berada di hadapannya dan tujuan yang terakhir adalah murid akan sentiasa mendapat kata-kata nasihat daripada guru yang mana dapat memberi semangat.

Fenomena yang terlihat bahwa membaca dan menghafal Al-Qur'an kurang diminati siswa. Bahkan ada anggapan belajar membaca dan menghafal Al-Qur'an sebagai suatu kewajiban di tempat pengajian, bukan di sekolah. Sementara itu jika ditinjau dari kemampuan membaca Al-Qur'an diketahui bahwa sebagian besar siswa kelas VI belum mampu membaca dan menghafal AlQur'an dengan lancar, serta kurang mengenal hukum-hukum tajwid, sehingga bacaan Al-Qur'an siswa tidak sesuai dengan kaidah tajwid dan makhrajnya. Untuk menghilangkan rasa bosan siswa mengikuti materi pelajaran Al-Qur'an, maka guru perlu melakukan berbagai inovasi untuk meningkatkan kemampuan siswa dalam membaca dan menghafal Al-Qur'an. Hal ini antara lain dapat dilakukan dengan menggunakan metode mengajar yang tepat. Salah satu metode yang dapat digunakan guru adalah metode Talaqqi.

Metode talaqqi yaitu cara pertemuan guru dan murid secara face to face. Jadi ketika ayat diturunkan maka Rasul pun segera menyampaikannya langsung kepada para sahabat, lalu para sahabat menyampaikannya kepada sahabat lain yang saat Rasul menyampaikan secara langsung itu mereka tidak sedang berada dalam Majlis tersebut. Metode Talaqqi tersebut memudahkan pengajar memilih cara yang tepat dalam menyampaikan ilmu, karena dengan bertemu langsung antara guru dan murid, membuat guru lebih mudah mengenali kepribadian murid. Metode Tallaqi adalah merupakan cara belajar Alquran dengan mengumpulkan siswa lalu secara antri menghadap guru untuk membaca hasil hafalannya. kelebihan dari metode ini adalah siswa secara langsung dapat mengetahui kekurangan dari hafalannya dan dapat bertanya jawab dengan gurunya,sehingga waktu yang dibutuhkan akan berbeda antara murid yang satu dengan yang lainnya karena materi untuk masing-masing peserta didik berbeda, dan jika metode ini dilaksanakan dengan baik dan benar dalam proses pembelajaran, maka kemampuan hafalan peserta didik akan meningkat secara cepat, tepat dan praktis.

Berdasarkan uraian pada pendahuluan di atas, penulis tertarik untuk melakukan Penelitian dalam bentuk jurnal yang judul "Meningkatkan Kemampuan Setoran Hafalan Al-Qur'an Melalui Metode Talaqqi pada Siswa Kelas VIB Sekolah Dasar Islam YAKMI Tahun 2018"

\section{KAJIAN TEORI}

\section{Konsep Menghafal Al-Qur'an}

Dalam bahasa Arab kata menghafal berasal dari kata حفظا- يحفظ - حفظ yang berarti menjaga, memelihara dan melindungi. ${ }^{6}$ Jadi menghafal adalah usaha sadar siswa dalam mengingat dan mengucapkan suatu kalimat supaya terjaga kemurniannya. Menurut Sa'adulloh "para ulama sepakat bahwa hukum menghafal Alquran adalah far u kifayah. Sedangkan menghafal sebagian surah Alquran seperti al-Fatihah adalah far u 'ain. Hal ini mengingat bahwa tidak sah shalat seseorang tanpa membaca Alquran". ${ }^{7}$ Arti menghafal menurut Abdul Aziz Rauf adalah suatu proses kegiatan mengulang baik dengan membaca atau mendengar, pekerjaan apapun jika sering diulang, pasti menjadi hafal. ${ }^{8}$ Dalam kamus besar Bahasa Indonesia disebutkan bahwa menghafal adalah berusaha meresapkan ke dalam fikiran agar selalu ingat. ${ }^{9}$ Menghafal Alquran merupakan hal yang penting dalam menjaga kemurnian dan keaslian Alquran.

\footnotetext{
6 Ahmad Warson Munawwir, Kamus al-Munawwir, (Surabaya: Pustaka Progresif, 2002), hal.279

7 Sa'adulloh, Cara Cepat Menghafal Al-Qur'an, (Jakarta: Gema Insani, 2008), hal. 19-20.

8 Abdul Aziz Rauf, Kiat sukses menjadi hafidz Qur'an, ( Yogyakarta: Yogya Press, 1999), hal. 86

9 Tim Pena Prima, Kamus Besar Bahasa Indonesia, (Jakarta: Gita Media Press, 1999), hal. 307
} 
Menurut para ulama sebagaimana dikemukakan Sa'adulloh ${ }^{10}$ ada beberapa faedah menghafal Alquran adalah sebagai berikut: (1) Memberikan kemenangan dan kebahagiaan di dunia dan akhirat. (2) mendapatkan anugerah dari Allah berupa ingatan yang tajam dan pemikiran yang cemerlang. (3) Mendorong seseorang yang hafal Al Quran untuk berprestasi lebih tinggi dari teman-temannya yang tidak hafal Alquran sekalipun umur, kecerdasan dan ilmu mereka berdekatan. (4) Penghafal Alquran memiliki identitas yang baik, akhlak dan perilaku yang baik.(5) Penghafal Alquran mempunyai kemampuan mengeluarkan fonetik Arab dari landasannya secara thabi'i (alami) sehingga biasa fasih berbicara dan ucapannya benar. (6) Jika penghafal Alquran mampu menguasai arti kalimat-kalimat di dalam Alquran, berarti ia telah banyak menguasai kosakata bahasa Arab, seakanakan ia telah menghafalkan sebuah kamus bahasa Arab. (7) Dalam Alquran banyak sekali kata-kata bijak (hikmah) yang sangat bermanfaat bagi kehidupan. Dengan menghafal Al Quran seseorang akan banyak menghafalkan kata-kata tersebut. (8) Bahasa dan Ushlub (susunan kalimat Al Quran) sangatlah memikat dan mengandung sastra Arab yang tinggi. (9) Dalam Alquran banyak sekali contoh-contoh yang berkenaan dengan ilmu nahwu dan sharaf. (10) Penghafal Alquran akan dengan cepat menghadirkan ayatayat hukum yang diperlukan dalam menjawab suatu persoalan hukum. (11) Penghafal Alquran setiap waktu akan selalu memutar otaknya agar hafalan Al Qurannya tidak lupa. Hal ini akan menjadikan hafalannya kuat, ia akan terbiasa menyimpan memori dalam ingatannya. Dengan demikian faedah menghafal Alquran sangat banyak. Hal ini tentu akan menjadi motivasi bagi umat Islam untuk menghafal ayat-ayat Alquran.

Dalam menghafal Alquran terdapat beberapa kaidah yang perlu diperhatikan, di antaranya:

a. Keikhlasan yang tulus dari hati serta tujuan yang baik menjadikan hafalan Alquran dan perhatiannya hanya untuk Allah swt.

b. Memperbaiki ucapan dan bacaan. Hal ini dapat dilakukan dengan cara mendengarkan

\footnotetext{
${ }^{10}$ Sa'adulloh, Cara Cepat Menghafal Al-Qur'an, op.cit, hal. 19-20
}

dari qori yang baik atau hafidz yang sempurna.

c. Menentukan batas hafalan setiap minggu.

d. Jangan melampaui hafalan wajib mingguan hingga hafalan menjadi benar dan sempurna.

e. Gunakan satu rasm untuk mushaf hafalan. Karena hafalan dapat terekam melalui AudioVisual.

f. Memahami ayat-ayat dari hafalan dan mengetahui keterkaitan antara sebagian ayat dengan ayat yang lainnya.

g. Jangan melewati bacaan wajib hingga anda mengikat yang pertama dengan yang terakhir.

h. Mengulangi dan memperdengarkan hafalan secara rutin.

i. Memperhatikan ayat-ayat yang serupa. Karena sangat banyak ayat-ayat yang serupa yang terdapat dalam Alquran hingga terkadang pembaca Alquran salah.

j. Gunakan kesempatan tahun-tahun emas untuk menghafal. Yaitu usia 5-10 tahun hingga 23 tahun.

k. Dengarkan kaset-kaset Alquran.

1. Lakukan shalat dengan membaca bacaan baik itu shalat fardhu atau shalat sunat. ${ }^{11}$

Untuk mendapatkan hafalan yang baik dan sempurna dengan target waktu yang diinginkan, maka kaidah yang telah diuraikan diatas dapat menjadi pertimbangan bagi penghafal Al-Qur'an. Dalam menghafal Al-Qur'an orang mempunyai metode dan cara yang bermacam-macam. Namun tujuan dari metode tersebut adalah upaya untuk dapat mempercepat hafalan dan memperlambat kelupaan. Proses menghafal Al-Qur'an dilakukan melalui proses bimbingan seorang guru agama Islam.

\section{Metode Talaqqi}

Metode talaqqi adalah pengajaran dimana guru dan murid berhadap-hadapan secara langsung pada pembelajaran Al-Qur'an dengan cara guru membaca terlebih dahulu kemudian disusul oleh siswa. Dengan penyampaian seperti ini, guru dapat menerapkan cara membaca huruf dengan benar melalui lidahnya. Sedangkan anak dapat melihat dan menyaksikan langsung praktik

11 Ahmad Salim Badwilan, Panduan Cepat Menghafal Alquran dan Rahasia- Rahasia Keajaibannya, ( Jogjakarta: Diva Press, 2009), hal. 86-90 
keluarnya huruf dari lidah guru untuk ditirukannya, yang disebut musyafahah (adu lidah) penyampaian seperti ini diterapkan oleh Rasulullah saw kepada para sahabat. Penyampaian ini cocok digunakan untuk tahap awal, proses pengenalan kepada anak-anak pemula, sehingga siswa mampu mengekspresikan bacaan-bacaan huruf dengan benar. Dengan kata lain istilah yang digunakan pada masa kini yaitu mempelajari AlQur'an secara face to face bersama seorang guru yang mahir. Orang yang ingin menghafal AlQur'an maka dia harus menerimanya dari ahli AlQur'an yang mendiktekan kepadanya, tidak cukup hanya dengan mempelajarinya sendiri sebab, salah satu keistimewaan Al-Qur'an yang terpenting adalah hafalan Al-Qur'an hanya boleh diterima secara talaqqi oleh ahlinya. ${ }^{12}$ Di dalam Al-Qur'an Allah SWT ada menyebut perkataan talaqqi sebagaimana firman-Nya yang berbunyi:

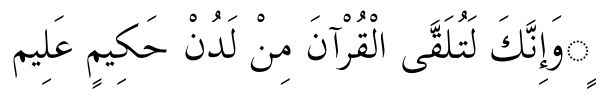

Artinya: "Dan sesungguhnya engkau (wahai Muhammad) benar-benar ditalaqqikan Al-Quran daripada sisi Allah Yang Maha Bijaksana lagi Maha mengetahui (melalui perantaraan Jibril)." (Q.S An-Naml: $6)^{13}$

\section{Kaidah Metode Talaqqi}

Kaidah metode talaqqi adalah dengan cara seorang murid duduk di hadapan gurunya untuk memperdengarkan bacaan Al-Qur'an secara langsung, di mana saja dengan syarat secara bertemu muka tanpa perantaraan alat lain. Guru akan menegur murid jika terdapat kesalahan dalam bacaannya serta membetulkan kesalahannya secara terus. Karena menghafal secara berangsur-angsur dari surat yang pendek dan mudah menuju surat panjang yang sulit jauh lebih mudah dilakukan. ${ }^{14}$ Kaedah ini diambil

12 Muhammad Habibillah dan Muhammad Asy Syinqithi, Kiat Mudah Menghafal Al-Qur'an, (Surakarta :Gazzamedia 2011), hal. 75

${ }^{13}$ Departemen Agama RI, Al-Qur'an Tajwid dan

Terjemahnya, op.cit, hal. 377

14 Muhammad Habibillah dan Muhammad Asy

Syinqithi, kiat Mudah Menghafal Al-Q ur' an, op.cit, hal. 78 daripada peristiwa turunnya wahyu yang pertama kepada Nabi Muhamad SAW ketika didatangi oleh malaikat Jibril AS di Gua Hira'. Malaikat Jibril AS membacakan Al-Qur'an surat Al-'Alaq ayat 1-5, kemudian Nabi Muhammad SAW mengikutinya. Proses pembacaan yang dilakukan oleh Nabi Muhammad S.A.W bersama Malaikat As ini adalah secara bertemu dan bukan di dalam mimpi atau melalui perantaraan yang lain. Sebagaimana firman Allah SWt di dalam AlQur'an yang berbunyi:

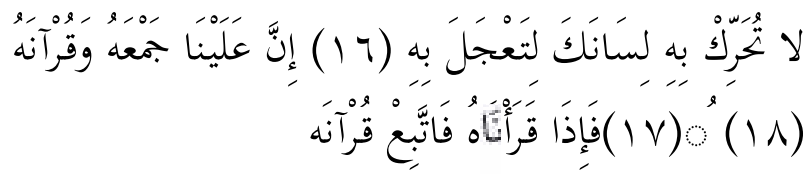

Artinya : " janganlah engkau (wahai Muhammad) menggerakkan lidahmu membaca Al-Quran (sebelum selesai dibacakan kepadamu) karena hendak cepat menghafal Al-Quran yang diturunkan kepadamu. Sesungguhnya Kamilah yang berkuasa mengumpulkan Al-Quran itu (dalam dadamu), dan menetapkan bacaannya (pada lidahmu);oleh itu, apabila Kami telah menyempurnakan bacaannya kepadamu (dengan perantaraan Jibril), maka bacalah menurut bacaannya itu. "(Surah Al-Qiamah: $16-18) .{ }^{15}$

Syeikh Hassan Ragab al-Muqri', pensyarah Al-Quran \& Al-Qiraat di Maahad Qiraat, Shoubra, Mesir menyatakan bahwa kaidah yang diamalkan di dalam sistem pengajian Al-Quran pada hari ini masih dikira sebagai talaqqi jika terdapat perkaraperkara berikut:

a. Guru mengartikan ayat- ayat Al Qur'an dengan lancar dan benar

b. Guru mengartikan hadits dengan lancar dan benar

c. Guru Menjelaskan isi materi Al-Qur'an dengan benar

${ }^{15}$ Departemen Agama RI, Al-Qur'an Tajwid dan Terjemahnya, op.cit, hal. 575-576 
d. Guru menjelaskan penerapan ilmu tajwid dalam Al-Qur'an

e. Guru mengoreksi bacaan siswa

\section{Kelebihan Talaqqi}

Talaqqi (musyafahah) merupakan warisan turun temurun daripada baginda Nabi Muhammad S.A.W. Diriwayatkan bahwasanya Nabi Muhammad S.A.W bertalaqqi Al-Qur'an bersama malaikat Jibril AS sekali setahun yaitu pada bulan Ramadhan dan pada tahun kewafatannya, Nabi Muhammad S.A.W bertalaqqi sebanyak dua kali. Para ulama tajwid amat menekankan konsep mempelajari Al-Qur' an secara talaqqi.

Antara lain kelebihannya adalah seperti berikut:

a. Dapat menjaga kebenaran bacaan al-Qur' an, hal ini akan berbeda jika membaca Al-Qur'an tanpa berguru atau hanya melalui buku-buku atau media-media elektronik yang kian berkembang pesat di zaman sekarang ini yang tidak dapat dipastikan sahih atau tidak sesuatu bacaan itu.

b. Bacaan seorang murid akan dikoreksi secara langsung oleh guru jika terdapat kesalahan dalam membaca.

c. Murid dapat melihat langsung pergerakan mulut guru apabila menyebut sesuatu bacaan. Hal ini disebabkan karena Al-Qur'an mempunyai keunikan tersendiri apabila kita membacanya. Ini amat berbeda jika bacaan Al-Qur'an itu hanya dipelajari daripada buku-buku atau media elektronik yang mana kita tidak dapat mengenal pasti bagaimana cara bacaan yang benar.

d. Murid lebih fokus ketika guru berada di hadapannya, dan akan berbeda hasilnya jika hanya belajar Al-Qur' an melalui buku-buku dan lain sebagainya.

e. Murid akan selalu mendapat kata-kata nasihat dari guru dalam mempelajari Al-Qur'an. Katakata berupa nasihat khusus berkaitan AlQur'an ini jarang dapat disampaikan melainkan orang yang memang telah berkecimpung dalam mempelajari ilmu AlQuran.

\section{Langkah - Langkah Metode Talaqqi}

Penggunaan metode talaqqi memudahkan guru ketika memilih cara yang tepat dalam menyampaikan ilmu, karna dengan bertemu langsung antara guru dan murid, membuat guru lebih mudah mengenali kepribadian murid. Keberadaan talaqqi merupakan bagian penting dalam penyebaran agama Islam, karena ada bagian yang tidak bisa di miliki oleh metodemetode pengajaran lainnya seperti saling mengerti antara guru dan murid, dan lain sebagainya. Adapun Langkah - langkah Metode Talaqqi Adalah sebagai berikut:

a. Guru memanggil siswa yang akan membaca Al-Qur'an

b. Siswa duduk di hadapan Guru mendengarkan bacaan Al-Qur'an

c. Guru mengoreksi bacaan siswa

d. Guru membacakan Al-Qur'an dihadapan Murid.

e. Guru meminta membacakan kembali ayat atau hadis yang telah dibaca

f. Guru menjelaskan hukum-hukum ilmu tajwid dalam Al-Qur'an yang telah di baca dan memberikan penjelasan secara keseluruhan mengenai ayat atau hadis yang dibacanya, baik sisi tajwid, bacaan, dan makna yang terkandung di dalamnya

\section{Pendekatan Penelitian}

Pendekatan yang dilakukan pada penulisan makalah ini adalah dengan pendekatan fenomenologi yang merupakan usaha mencari arti pengalaman atau peristiwa dalam kehidupan. Peneliti menghimpun data berkenaan konsep, pendapat, pendirian, sikap, penilaian, dan pemberian makna terhadap situasi atau pengalaman dalam kehidupan. Sehingga peneliti mengindentifikasi hakikat pengalaman manusia tentang suatu fenomena tertentu.

Dengan demikian penelitian ini merupakan suatu tindakan untuk mencari pemecahan masalah yang berkaitan dengan upaya meningkatkan kemampuan siswa membaca dan menghafal Alquran. Penelitian tindakan yang digunakan adalah penelitian partisipan, yaitu peneliti terlibat secara penuh dan langsung dalam proses penelitian mulai dari awal hingga akhir. Dan peneliti berkolaborasi dengan wali kelas untuk membantu mencari solusi yang efektif dalam pembelajaran dengan menerapkan metode talaqqi 
sebagai upaya memperbaiki dan meningkatkan kemampuan membaca dan menghafal Alquran siswa.

\section{B. PEMBAHASAN DAN HASIL PENELITIAN}

1. Deskripsi Data

a. Tinjauan Historis

Sekolah Dasar Islam YAKMI adalah sekolah swasta yang terletak di jalan Balita XI Kelurahan Kunciran Indah Kecamatan Pinang Kota Tangerang. Berdasarkan hasil wawancara dengan istri yakni Ibu $\mathrm{Hj}$ Marlinah yang mana beliau adalah istri dari almarhum Drs.H. Dauad Afifi, S.H, M.H yang menjabat sebagai ketua umum Yayasan YAKMI maka dapat disimpulkan bahwa awal mula berdirinya Sekolah Dasar Islam YAKMI pada tahun 1985, yang diawali dengan mengontrak sebuah rumah di jalan Balita VIII. Tujuan dari pendirian lembaga ini yang mana wilayah ini dulu tergabung dalam Kecamatan Cipondoh belum ada lembaga pendidikan yang berciri khas Keislaman serta letak sekolah Negeri yang jauh dari komplek perumahan. Untuk memenuhi keinginan warga serta tokoh masyarakat yang lain agar di kawasan tersebut ada lembaga pendidikan yang lebih formal dan tertata dengan rapi dan terstrukur, maka dibuatlah lembaga pendidikan Islam yang dapat menghasilkan lulusan yang bermutu sesuai ajaran Islam. ${ }^{16}$ Dengan semakin pesatnya wilayah Kunciran menjadi kawasan padat pemukiman komplek perumahan serta tuntutan kesetaraan antara pendidikan di Sekolah Dasar Islam YAKMI dengan pendidikan Sekolah Dasar Negeri yang lain, maka pada tahun 1990 Sekolah Dasar Islam YAKMI didaftarkan menjadi lembaga yang diakui oleh pemerintah dan terakui dan berstatus disamakan.

b. Kegiatan Pendidikan TPA di SD Islam YAKMI

Kegiatan pendidikan Taman Pendidikan AlQur'an (TPA) adalah salah satu jenjang pendidikan empat tahu, TPA di Sekolah Dasar Islam YAKMI yang berdiri pada tahun 1998 menjadi program unggulan sekolah. Kegiatan
TPA hanya diikuti oleh siswa dengan jumlah 363 siswa yang terdiri dari kelas III sampai dengan siswa kelas VI yang dimulai pada pukul 13. 50 sampai pukul 15.05 diampu oleh 13 orang guru sebagai penanggung jawab kegiatan TPA

\footnotetext{
${ }^{16}$ Hasil wawancara dengan ibu $\mathrm{Hj}$ Marlinah di

Ruang Bendahara Yayasan pada hari Senin tanggal 26 November 2018 pukul $09.30-10.00$
} 
Tabel. 2

Data guru TPA SD Islam YAKMI Tahun 2018/2019

\begin{tabular}{|c|l|l|c|}
\hline No & \multicolumn{1}{|c|}{ Nama } & $\begin{array}{c}\text { Tugas } \\
\text { Mengajar }\end{array}$ & $\begin{array}{c}\text { Jumlah siswa } \\
\text { yang diampu }\end{array}$ \\
\hline 1 & Ahmad Fahrurozi, S.Pd & $\begin{array}{l}\text { Koordinator } \\
\text { TPA }\end{array}$ & - \\
\hline 2 & Amal Fathullah & $\begin{array}{l}\text { Koordinator } \\
\text { TPA }\end{array}$ & - \\
\hline 3 & Burhanuddin, S.Pd.I & Kelas VIA & 32 \\
\hline 4 & Imam Mashud, M.Ag & Kelas VI B & 27 \\
\hline 5 & Amin Zuhdi & Kelas VI C & 31 \\
\hline 6 & Astinah & Kelas VI D & 25 \\
\hline 7 & Ahmad Fiqri & Kelas VA & 30 \\
\hline 8 & Muhammad Yasin & Kelas V B & 25 \\
\hline 9 & Iknur Rahmat, S.Pd.I & Kelas V C & 26 \\
\hline 10 & Eko Hardiansyah & Kelas IVA & 26 \\
\hline 11 & Sulaiman & Kelas IV B & 23 \\
\hline 12 & Muhammad Aby & Kelas IVC & 23 \\
\hline 13 & Yusuf Bahtiar & Kelas III A & 30 \\
\hline 14 & Abdullah Syakir & Kelas III B & 33 \\
\hline 15 & Isnani Ismiyatun & Kelas III C & 32 \\
\hline & Jumlah & 13 & $\mathbf{3 6 3}$ \\
\hline
\end{tabular}

Kegiatan pembelajaran TPA di SD Islam YAKMI dilakukan dengan memadukan kurikulum keagamaan yang mengacu pada Kurikulum
Direktorat Jenderal Pendidikan Islam Kantor Kementerian Agama. Adapun materi pada kegiatan TPA terjadwal sebagai sebagai berikut:

Tabel. 3

Kegiatan TPA SD Islam YAKMI Tahun Pelajaran 2018/2019

\begin{tabular}{|c|l|l|l|}
\hline No & Hari & \multicolumn{1}{|c|}{ Jam } & \multicolumn{1}{c|}{ Kegiatan } \\
\hline \multirow{3}{*}{1} & \multirow{3}{*}{ Senin } & $13.40-14.15$ & Kajian Al-Qur'an dan Hadits \\
\cline { 3 - 4 } & & $14.15-14.50$ & Mengaji \\
\cline { 3 - 4 } 2 & \multirow{3}{*}{ Selasa } & $14.50-15.15$ & Hafalan Al-Qur'an \\
\hline & & $13.40-14.15$ & Kajian Aqidah Akhlak \\
\cline { 3 - 4 } & & $14.15-14.50$ & Mengaji \\
\hline \multirow{3}{*}{3} & \multirow{3}{*}{ Rabu } & $14.50-15.15$ & Hafalan Al-Qur'an \\
\cline { 3 - 4 } & & $13.40-14.15$ & Kajian Fiqih \\
\hline \multirow{3}{*}{4} & \multirow{3}{*}{ Kamis } & $14.15-14.50$ & Mengaji \\
\cline { 3 - 4 } & & $14.50-15.15$ & Hafalan Al-Qur'an \\
\cline { 3 - 4 } & & $13.40-14.15$ & Kajian Sejarah Islam \\
\cline { 3 - 4 } & & $14.15-14.50$ & Mengaji \\
\hline
\end{tabular}

c. Tujuan Kegiatan TPA SD Islam YAKMI

Adapun tujuan dari kegiatan TPA di SD

Islam YAKMI adalah sebagai berikut:
1) Siswa dapat mengagumi dan mencintai $\mathrm{Al}$ Quran sebagai bacaan istimewa dan pedoman utama. 
2) Siswa dapat terbiasa membaca Al Quran dengan lancar dan fasih serta memahami hukum-hukum bacaannya berdasarkan kaidah ilmu tajwid.

3) Siswa dapat melaksanakan shalat lima waktu dengan tata cara yang benar dan menyadarinya sebagai kewajiban sehari-hari

4) Siswa dapat menguasai hafalan sejumlah surat pendek, ayat pilihan, dan doa harian.

5) Siswa dapat mengembangkan perilaku sosial yang baik sesuai tuntunan Islam dan pengalaman pendidikannya.

6) Siswa dapat menulis huruf arab dengan baik dan benar.

d. Keadaan Hafalan Siswa TPA SD Islam YAKMI

Keadaan hafalan pada siswa TPA SD Islam pada tahun ajaran sebelumnya tidak pernah teridentifikasi dengan baik dan tercatat pada lembar muttaba'ah, sehingga sulit untuk dicari kelemahan dan kekuatan yang dimiliki oleh siswa.
Karena alasan tersebut maka pada tahun ajaran 2018/2019, pihak sekolah mengadakan lembar mutaba'ah yang berguna untuk mengukur dari target yang telah ditentukan yakni dalam satu tahun pelajaran di tahun 2018/2019, seluruh siswa mempunyai data hafalan pada juz ke-30 yang valid dan dapat dipertanggungjawabkan.

e. Kegiatan Metode Tallaqi pada kegiatan setoran hafalan Al-Qur' an

Setelah di data jumlah seluruh siswa pada kegiatan TPA, maka tugas koordinator adalah membagi jumlah siswa pada setiap kelas untuk setoran hafalan seminggu sekali sesuai jadwal yang telah dibuat untuk setiap harinya jumlah siswa yang setoran hafalan setiap hari rata-rata berjumlah 6-10 siswa untuk setiap harinya. Hal ini dilakukan dengan tujuan agar siswa yang melakukan setoran hafalan yang dimulai pada pukul 14.50- 15.15 dapat terlayani dengan maksimal. Adapun Pembagian waktu kegiatan setoran hafalan adalah sebagai berikut:

Tabel. 4

Daftar Kegiatan Setoran Hafalan

SD Islam YAKMI Tahun 2018

\begin{tabular}{|c|l|c|c|}
\hline No & \multicolumn{1}{|c|}{ Nama } & Jadwal Setoran & Ket \\
\hline 1 & Ahmad Zaky & Senin & \\
\hline 2 & Ahmadin Nejad & Senin & \\
\hline 3 & Alvito Raditya & Senin & \\
\hline 4 & Ario Priyanka Putra & Senin & \\
\hline 5 & Ariq Raditya & Senin & \\
\hline 6 & Dani Agusetiawan & Selasa & \\
\hline 7 & Dafa Irwantoro & Selasa & \\
\hline 8 & Diesa Ramadhana & Selasa & \\
\hline 9 & Fareno Aziz P & Selasa & \\
\hline 10 & Fawwaz A.K & Selasa & \\
\hline 11 & Mugen Repsolano & Selasa & \\
\hline 12 & M. Azuari & Selasa & \\
\hline 13 & M. Lammy Ilham & Selasa & \\
\hline 14 & M. Luthfi .H & Selasa & \\
\hline 15 & M. Nashwan I.R & Rabu & \\
\hline 16 & M. Ridho. M & Rabu & \\
\hline 17 & M. Rifqi. N & Rabu & \\
\hline 18 & M. Taufik. W & Rabu & \\
\hline 19 & Nehan Ruwayfi & Rabu & \\
\hline 20 & Rangga Raditya & Rabu & \\
\hline 21 & Rexi Pandu. W & & \\
\hline & & & \\
\hline
\end{tabular}




\begin{tabular}{|c|l|c|c|}
\hline No & \multicolumn{1}{|c|}{ Nama } & Jadwal Setoran & Ket \\
\hline 22 & Reyvan A.A & Kamis & \\
\hline 23 & Rizqi Abdullah. F & Kamis & \\
\hline 24 & Rivqi A & Kamis & \\
\hline 25 & Siraj Ar-Rizal & Kamis & \\
\hline 26 & Teguh Prasetyo & Kamis & \\
\hline 27 & Yusuf Hamdani & Kamis & \\
\hline
\end{tabular}

f. Adapun tata cara sistem setoran melalui metode tallaqi pada kegiatan TPA di Sekolah Dasar Islam YAKMI adalah sebagai berikut:

1) Siswa yang tidak terjadwal pada waktu pelaksanaan agar pulang ke rumah masingmasing.

2) Siswa yang akan melakukan setoran untuk mempersiapkan diri untuk wudhu yang akan dimulai dari jam 14.50

3) Guru TPA mengkondisikan siswa yang telah dibagi dengan jumlah tiap kelompok 8-10 siswa

4) Setiap siswa mendapat giliran untuk membaca dan menyetorkan hafalannya

5) Guru mengoreksi dan memperhatikan bacaan siswa

6) Guru mencatat hasil setoran siswa pada lembar mutaba'ah

7) semua guru TPA untuk kumpul di minggu terakhir setiap bulan untuk rapat, melaporkan dan mengevaluasi kegiatan hafalan pada setiap kelas.

g. Kriteria penilaian pada setoran hafalan Al-

Qur'an Melalui Metode Talaqqi

Setelah siswa melakukan kegiatan setoran hafalan, maka guru mencatat hasil setoran siswa pada lembar mutaba'ah yang telah diberikan oleh pihak sekolah. Kriteria pencatatan sederhana yang dibuat oleh sekolah, apabila dilakukan secara kontinyu maka akan terlihat hasilnya tanpa melakukan manipulasi data agar terlihat bagus. Mencatat apa adanya merupakan sikap yang terbaik agar marwah guru selalu terjaga. Adapun hasil setoran dapat ditaruh pada kolom sebagai berikut:

1) Sekedar Hafal

Kriteria setoran pada kolom ini dilakukan bagi siswa yang belum lancar membaca AlQur'an, namun hafal karena ada pembiasaan melalui kegiatan Tasmi

2) Lancar

Kriteria setoran pada kolom ini dilakukan bagi siswa yang sudah lancar membaca AlQur'an, namun kaidah tajwidnya belum tepat

3) Tajwid

Kriteria setoran pada kolom ini dilakukan bagi siswa lancar membaca Al-Qur'an dengan baik makhrajnya dan sesuai tajwid.

2. Analisis Hasil Penelitian

Setelah hasil penelitian didapatkan dan dianalisis, maka didapatkan data untuk dibahas sebagai berikut:

a. Hasil Setoran Hafalan Al-Qur'an Melalui Metode Talaqqi

Hasil setoran hafalan Al-Qur'an melalui metode Tallaqi pada siswa kelas VIB di dapat sebagai

berikut:

\section{Tabel 5}

Data Hasil Mutaba' ah Setoran Hafalan Siswa

SD Islam YAKMI Tahun Ajaran 2018/2019

\begin{tabular}{|c|l|c|c|c|c|c|}
\hline \multirow{2}{*}{ No } & \multirow{2}{*}{ Nama } & \multicolumn{2}{|c|}{$\begin{array}{c}\text { Jumlah Setoran dan jenis } \\
\text { penilaian }\end{array}$} & \multirow{2}{*}{$\begin{array}{c}\text { Jumlah } \\
\text { Hafalan }\end{array}$} & \multirow{2}{*}{ Ket } \\
\cline { 3 - 5 } & & Hafal & Lancar & Tajwid & & \\
\hline 1 & Ahmad Zaky & 3 & 14 & - & 17 & \\
\hline 2 & Ahmadin Nejad & 3 & 14 & - & 17 & \\
\hline 3 & Alvito Raditya & 1 & 22 & - & 23 & \\
\hline 4 & Ario Priyanka P & 1 & 18 & - & 19 & \\
\hline 5 & Ariq Raditya & 1 & 24 & - & 25 & \\
\hline
\end{tabular}




\begin{tabular}{|c|l|c|c|c|c|c|}
\hline \multirow{2}{*}{ No } & \multicolumn{1}{|c|}{ Nama } & \multicolumn{2}{c|}{$\begin{array}{c}\text { Jumlah Setoran dan jenis } \\
\text { penilaian }\end{array}$} & \multirow{2}{*}{$\begin{array}{c}\text { Jumlah } \\
\text { Hafalan }\end{array}$} & \multirow{2}{*}{ Ket } \\
\cline { 3 - 6 } & & Hafal & Lancar & Tajwid & & \\
\hline 6 & Dani Agus & 1 & 27 & - & 28 & \\
\hline 7 & Dafa Irwantoro & - & 18 & - & 18 & \\
\hline 8 & Diesa Ramadhana & 1 & 21 & - & 22 & \\
\hline 9 & Fareno Aziz P & 1 & 19 & - & 20 & \\
\hline 10 & Fawwaz A.K & 2 & 17 & - & 19 & \\
\hline 11 & Mugen Repsolano & 1 & 10 & - & 11 & \\
\hline 12 & M. Azuari & - & 16 & - & 16 & \\
\hline 13 & M. Lammy Ilham & 1 & 23 & - & 24 & \\
\hline 14 & M. Luthfi .H & 1 & 20 & - & 21 & \\
\hline 15 & M. Nashwan I.R & - & 21 & 4 & 25 & \\
\hline 16 & M. Ridho. M & - & 20 & 8 & 28 & \\
\hline 17 & M. Rifqi. N & 2 & 17 & - & 19 & \\
\hline 18 & M. Taufik. W & 3 & 11 & - & 14 & \\
\hline 19 & Nehan Ruwayfi & 1 & 16 & - & 17 & \\
\hline 20 & Rangga Raditya & - & 19 & - & 19 & \\
\hline 21 & Rexi Pandu. W & 1 & 22 & - & 23 & \\
\hline 22 & Reyvan A.A & 2 & 20 & - & 22 & \\
\hline 23 & Rizqi Abdullah. F & 3 & 21 & - & 24 & \\
\hline 24 & Rivqi A & - & 23 & - & 23 & \\
\hline 25 & Siraj Ar-Rizal & 2 & 19 & - & 21 & \\
\hline 26 & Teguh Prasetyo & - & 17 & - & 17 & \\
\hline 27 & Yusuf Hamdani & 1 & 18 & - & 19 & \\
\hline & Jumlah & $\mathbf{3 2}$ & $\mathbf{5 0 7}$ & $\mathbf{1 2}$ & $\mathbf{5 5 1}$ & \\
\hline & Rata-Rata & $\mathbf{1 , 2}$ & $\mathbf{1 9}$ & $\mathbf{0 . 4}$ & $\mathbf{2 0}$ & \\
\hline
\end{tabular}

Dari data di atas dapat diketahui bahwa jumlah surat pada juz ke 30 ada 36 surat, dari kegiatan setoran hafalan siswa yang telah dilakukan dari bulan Juli sampai bulan November 2018, rata-rata seluruh siswa pada kelas VIB sudah hafal 20 surat atau 55\% dari jumlah surat pada juz ke-30 sudah dihafal oleh seluruh siswa kelas VIB. Dengan demikian sangat optimis untuk target hafal pada juz ke-30 sebanyak 36 surat dapat tercapai di bulan April 2019 ketika akan diadakan uji publik hafalan al-qur'an juz ke-30 yang akan dipusatkan di Masjid Nurul Iman Kelurahan Kunciran Indah Kecamatan Pinang Kota Tangerang. Dengan demikian penggunaan metode talaqqi dalam kegiatan setoran hafalan siswa SD Islam YAKMI Tahun 2018/2019 pada umumnya sangat membantu keberhasilan siswa dalam proses menghafal al-Qur' an pada juz ke-30.

\section{SIMPULAN}

Dari hasil penelitian tersebut di atas maka dapat disimpulkan sebagai berikut:

1. Keadaan hafalan pada siswa TPA SD Islam pada tahun ajaran sebelumnya tidak pernah teridentifikasi dengan baik dan tercatat pada lembar mutaba'ah, sehingga sulit untuk dicari kelemahan dan kekuatan yang dimiliki oleh siswa dalam hafalan Al-Qur'an.

2. Kegiatan pelaksanaan setoran hafalan dengan menggunakan metode talaqqi pada siswa khususnya kelas VI B, maka guru mencatat hasil setoran siswa pada lembar mutaba'ah yang telah diberikan oleh pihak sekolah. Kriteria pencatatan sederhana yang dibuat oleh sekolah, apabila dilakukan secara kontinyu maka akan terlihat hasilnya tanpa melakukan manipulasi data agar terlihat bagus.

3. Hasil yang didapat dari kegiatan setoran hafalan siswa kelas VIB dengan menggunakan metode talaqqi adalah setoran hafalan siswa yang telah dilakukan dari bulan Juli sampai bulan November 2018, rata-rata 
seluruh siswa pada kelas VIB sudah hafal 20 surat atau 55\% dari jumlah surat pada juz ke30 yakni 36 surat sudah dihafal oleh seluruh siswa kelas VIB. Dengan demikian sangat optimis untuk target hafal pada juz ke-30 sebanyak 36 surat dapat tercapai dan dapat dilakukan uji publik hafalan Al-Qur'an pada bulan April 2019.

\section{DAFTAR PUSTAKA}

As-Sirjani, Raghib dan Khaliq, A. Abdurrahman, 2007, Cara Cerdas Hafal Al-Qur'an, Solo: Aqwam.
Badwilan, Salim, Ahmad, 2009, Panduan Cepat Menghafal Alquran dan Rahasia- Rahasia Keajaibannya, Jogjakarta: Diva Press

Habibillah, Muhammad dan Asy Syinqithi, Muhammad, 2011, Kiat Mudah Menghafal Al-Qur'an,

Departemen Agama RI, 2016, Al-Qur'an Tajwid dan Terjemahnya, Bandung: Diponegoro

Munawwir, Warson, Ahmad, 2002, Kamus alMunawwir, Surabaya: Pustaka Progresif

Rauf, Aziz, Abdul, 1999, Kiat sukses menjadi hafidz Q ur'an, Yogyakarta: Yogya Press

Shihab, Quraish, M, 2002, Membumikan alQuran, Jakarta: Lentera Hati

Tim Pena Prima, 1999, Kamus Besar Bahasa Indonesia, Jakarta: Gita Media Pres. 